\title{
Foetal cleft anomalies of the anterior chamber
}

\author{
RONALD F. LOWE
}

From the Glaucoma Unit, The Royal Victorian Eye and Ear Hospital, Melbourne, and the Ophthalmic Research Institute of Australia

Sampaolesi (1968) described, and carefully illustrated, malformations in the region of the optic cup showing as depression of the surface of the iris, recession of the angle, and increase of the anterior chamber depth in that sector. Finding these signs in adults with chronic glaucoma, he postulated a more widespread disturbance of the angle structure and considered that the glaucoma was a form of secondary glaucoma having a congenital origin but with late onset.

For several years independently on the other side of the world, I have been observing these malformations during the examination of patients with angle-closure glaucoma, and I have come to different conclusions.

Fuchs (1885) described a frequent hypoplasia of the mesenchymal layer of the iris in the region of the foetal ocular cleft. Further descriptions were added by Arnold (I9I I), Streiff (1915), and Mann (1937). The observations were confirmed by Vogt (I94I) and Berliner (1949), who gave illustrations in their text books. These authors describe segmental iris thinning inferiorly, sometimes with extensions centrally that caused a small notch in the inferior margin of the pupil. Their publications preceded widespread gonioscopy, so that descriptions of the angle are lacking except that Streiff (1916) illustrated, in section, a steeper depth of the angle in this place.

\section{Descriptions}

The anomalies show as consequences of minor irregularities in closure of the foetal cleft. Characteristically the situation is inferonasal, but may be directly inferior or occasionally slightly inferotemporal in positions found for congenital colobomata of the iris.

Minimum anomalies show as dimples in the periphery of the iris, usually suggesting slight fibrosis at the site of closure of this part of the cleft. These dimples are readily seen when the remainder of the iris is convex as a result of relative pupil block in primary angle-closure glaucoma (Fig. I).

More extensive irregularities show as larger depressions of the peripheral iris or extensions centrally that cause a slight thinning of the iris stroma even as far as the inferior margin of the pupil to produce a slight notching there (Fig. 2). The depression of the peripheral iris may also become more obvious with pupil dilatation after iridectomy, when folded iris crowds the angle elsewhere (Fig. 3). Peripheral foetal cleft anomalies may be seen open to the depths of angles that are otherwise completely occluded.

\section{Significance}

The generally agreed frequency of these anomalies indicates that they have no adverse effect on ocular function. My observations in their relationship to angle-closure glaucoma 


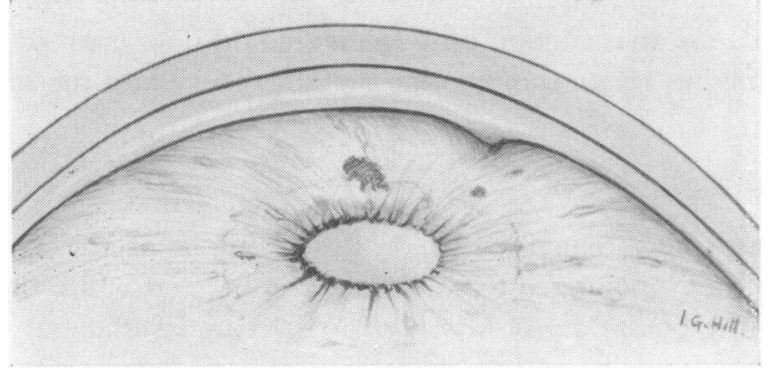

FIG. I Peripheral iris dimple with convex iris and narrow angle.

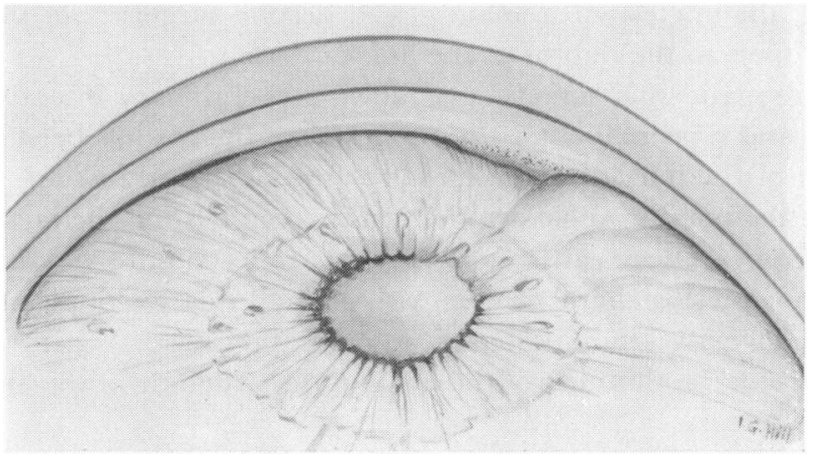

FIG. 2 Peripheral iris indentation with radial iris anomaly and notched pupil.

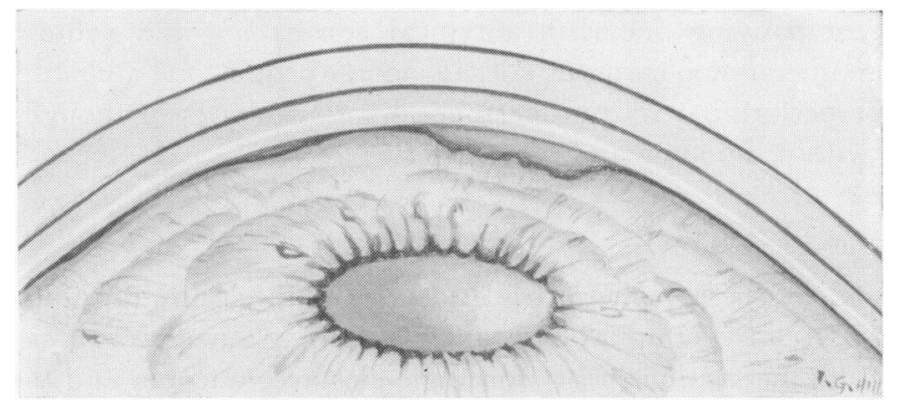

FIG. 3 With pupil dilatation, the peripheral iris indentation remains wide while the angle is crowded elsewhere.

show no increased tendency for chronic glaucoma to follow peripheral iridectomy for the control of angle closure.

For glaucoma, the significance of these foetal cleft anomalies appears to be related to theories concerning the mechanism of angle closure and the possibility of reducing its risk.

The suction theory of angle closure

The importance of relative pupil block as an essential feature of primary angle-closure glaucoma now appears beyond dispute, but the mechanism of actual angle closure still has some controversial aspects.

Czermak ( 1897 ) postulated that the peripheral iris was sucked against the trabeculae. This concept was supported and developed by Posner (1953), who later stated (Posner I955) that the iris suction hypothesis presupposed not only the presence of a narrow angle but also a continuous and unbroken surface of the iris where it comes into contact with the cornea to make a watertight seal. If the seal were broken in any place, the suction would be lost and the angle would open. Further, in the fellow eyes of some cases of primary angle-closure glaucoma, he found crypts, in the peripheral iris stroma which he believed 
prevented angle closure by allowing communication of aqueous to the annulus between the convex iris and trabeculae so that suction onto the iris could not occur (Posner, 1955).

The congenital cleft anomalies refute the circular suction theory and the importance of peripheral iris crypts.

\section{The suction theory refuted}

In some cases of acute angle-closure glaucoma, a deep dimple of the peripheral iris $\frac{5}{\bar{N}}$ associated with a corresponding opening into the angle can be seen while the remainder $\stackrel{\mathbb{Q}}{\Omega}$ of the angle is closed and the ocular tension is high. If treated sufficiently early these angles will open; but, if the patients have delayed attending until firm peripheral anterior $\overrightarrow{0}$ synechiae have formed, the angles will remain closed despite surgery; yet the peripheral clefts may still be seen open to the depths of the angles.

In acute angle-closure glaucoma, sometimes following preliminary intensive treatment흥. which opens the angle, and especially after the convexity of the iris has been abolished by surgery, a large section of the inferior angle may become suprisingly wide. Gonioscopically, the full depths of the inferior angle are then easily seen despite the angle remaining $\infty$ narrow above. Such appearances cause surprise that angle closure has occurred, but $\frac{}{5}$ these are typical shallow anterior chamber eyes with enough relative pupil block to cause angle closure by iris convexity from posterior aqueous pressure. When the posterior aqueous pressure is relieved, the thinning of the iris and the widening of the angle from the cleft anomaly become obvious.

More rarely, a large inferior depression of the peripheral iris may be unilateral and seen in a fellow eye accompanying one with a typical convex iris and acute angle-closure:glaucoma. In these uncommon cases, usually in elderly people, one anxiously debates the recommendation for performing routine peripheral iridectomy even though the anterior chamber depth be within the known range of risk.

\section{Summary}

Congenital depressions of the peripheral iris associated with closure of the foetal cleft are relatively common. Relative pupil block angle-closure glaucoma can occur in their卷 presence. They refute the suction theory for angle-closure glaucoma and the proposition that peripheral iris crypts prevent angle-closure glaucoma. Foetal cleft anomalies in eyes subject to angle-closure glaucoma were found to have no significance for causing chronic glaucoma.

\section{References}

ARNOLD, P. (191 I) Klin. Mbl. Augenheilk., 49 (2) (n.s. 12), 45I

BerLiner, M. L. (1949) "Biomicroscopy of the Eye", vol. 2, p. 796. Hoeber, New York

czermak, w. (1897) Prag. med. Wschr., 22, I

FUCHS, E. (1885) v. Graefes. Arch. Ophthal., 31, pt 3, p. 39

manN, I. (1937) "Developmental Anomalies of the Eye", p. 248. University Press, Cambridge

POSNER, A. (1953) Amer. J. Ophthal., 36, 185

SAMPAOLESI, R. (1968) "Modern Problems in Ophthalmology", First South American Glaucoma

Symposium, 1966, vol. 6, p. ı06. Karger, Basel and New York

STREIFF, J. (1915) Klin. Mbl. Augenheilk., 54, 33

voGt, A. (194I) "Handbook and Atlas of the Slit-Lamp Microscopy of the Living Eye", vol. 3,

p. 781. Schweizer, Zurich 